\title{
Social and technical aspects in solar system design
}

\author{
Dorota Wójcicka-Migasiuk ${ }^{1, *}$, Andrzej Chochowski ${ }^{2}$ \\ ${ }^{1}$ Lublin University of Technology, Faculty of Fundamental Engineering, Lublin, Poland \\ ${ }^{2}$ Warsaw University of Life Sciences, Warsaw, Poland \\ *Tel: +48 81 5384453, Fax: +48 81 5384706,E-mail: d.wojcicka-migasiuk@pollub.pl
}

\begin{abstract}
The paper defines and describes factors that should be considered when hybrid energy supply systems that incorporate solar systems in particular are planned. In the first point, the author establishes the hierarchy of criteria to apply at subsequent phases of the decision processes carried out when renewable energy systems are to be used. To do this, the authors take the advantage of shortly described case studies: a solar hot water system in an elderly house and an integrated system of steam boilers together with heat recovery from a cooling system in connection with solar heating in a food production plant, etc. Then, the paper indicates the necessity of energy simulations prior to taking up the decisions of localization and to final verification of the project. The example of the simulation method called equivalent thermal network is mentioned in the comparison to the advantages and disadvantages of the other software described. Some forms of promotion are presented, which can be applied to positively stimulate the sustainable development of the use of renewable sources in the European central eastern region on the background of a short comparison.
\end{abstract}

Keywords: local availability, hybrid systems, sustainable development

\section{Introduction}

Hybrid systems in relation to energy supply are the systems that incorporate different media such as electric current, flowing fluids or solid massive elements to carry out different forms of energy from various sources either renewable or conventional. They are also called integrated systems and can combine a traditional boiler gas fired, a heat pump transferring ground heat or the heat from solar thermal collectors, a usually small photovoltaic system supplying electrical energy for circulation pumps and somehow integrated a passive system such as e.g. solar walls. The particular composition is determined by operational conditions, energy source localization, availability and its form, and by other factors that influence the rational use of energy. The decisions can be taken up after thorough consideration of:

-local climatic conditions,

-social aspects that influence the cycle of energy demand,

-object character,

-technological aspects resulting from selected devices designed for the system,

-economical factors that determine investment capabilities in the frame of the analyzed enterprise and

-the cost of operation of the whole hybrid system.

The paper presents the description of the influence of selected factors on design and decision processes related to appropriate energy supply system and on the realization of objects that use solar energy. There is a vast diversity of social aspects and problems of matching between the demand and solar energy availability in a perspective characteristic for mid-severe climate, characteristic for central - eastern Poland. The procedure of careful analysis describes the most important contracting factors such as:

-high solar gain and low ambient temperature,

-high social acceptation and cost exaggerating investment capabilities in the region,

-standard regulations characteristic for the country and the region and availability of simulation tools, and with special attention

-the applicability of available simulation tools. 


\section{Methodology}

The selection and decisive criteria can be divided in some hierarchy. It is obvious for engineers that the good will of having a system to supply renewable energy cannot be decisive for selection of components for the particular object. It is questionable, however, if the negative will (quite common in some societies) can be decisive for the resignation and if the decision should not be taken by local authority on the basis of justified technical reasons and natural conditions, having in mind the rational use of energy and environment protection. It is a distant goal to reach the situation when such justification is obligatory to potential investors. On this distant way to reach this goal either social mentality must undergo its process of evolution towards higher responsibility for the environment or legislation and standards must be established to rule new attempt to the selection of energy sources. The widely understood education drawing the attention to all mentioned determinants could be very helpful on this way to assume proper hierarchy in the processes of investment, design, realization, maintenance of systems and exploitation of resources to reach the final result established as sustainable development.

Usually, attempting the design process for a particular object, its localization and character is already established, but sometimes, we have a chance to adjust the localization for better exposition to solar radiation or for advantageous distribution of ground collectors and slightly adjust the waveform of load to the cycle of energy availability through some change of habits or technology. The principal idea of hybrid systems is not the most extensive use of all renewable energy sources (res) in one system but the most reasonable integration of those that are convenient for the localization and the object character. Country regions are comparatively flexible in fitting the localization to the needs of effective heating systems and this meets another fact that the systems that are used there are usually outdated and contain low effective boilers fuelled with coal or are expensive such as boilers fuelled with liquid gas or gasoil because of the cost of these fuels. In the first phase of design the availability and economics of resources is considered. The paper is focused on solar energy thermal conversion integrated within hybrid systems because widely understood conversion of solar energy has its special conditions and restrictions worth analyses.

The systems that use direct and dispersed beam require south oriented exposition with possible adjustment to horizontal plane, and thus should be placed on the ground or tilted roofs. They need the coincidence of load waveform and the cycle of availability as much as possible to avoid damage resulting from overheating of elements or heat loss because of extended accumulation. These systems are used:

- for hot water systems: in food industry, for sanitary and living purposes in permanently occupied buildings (SDHW) and to contribute low temperature heating systems, especially

- floor heating systems,

- to heat process water: in fish breeding ponds, to water glasshouse plants and to heat the ground,

- in drying processes of many purposes to contribute technological halls (air collectors and passive solar systems), especially biomass drying for solid biofuels,

Systems that cooperate with heat pumps in heating systems either in central heating or hot water systems require additional supply from electric grid and providing cooling power from the bottom source of so called bottom energetic potential i.e. from the ground, for example. They can have the form of:

- ground water wells, which require proper soil absorption to receive water from absorption wells, proper localization in a distance to each other and good quality of soil to protect durability of drilled objects, 
- horizontal and vertical heat exchangers that require big undeveloped land area. One should remember that undeveloped does not mean unused. The terrain with ground collectors underneath can serve as a parking place, sports yard, nice flower bed or grass and only big root trees must be avoided.

Boilers can be fuelled with biofuels but each case must be considered if the particular localization is economically justified in the aspect of transport cost. It is difficult to describe biofuels as one source of energy because they are diversified as much as biomaterials and processes used for their generation. Shortly describing, the generation can also be understood as origin and is the classifying factor for biofuels. The first generation biofuels are produced directly from eatable plants in fermentation and trans-estrification processes and have similar limitations as food raw material. The second generation biofuels are produced from biomass or non eatable seeds having in mind that waste material is its origin. The third generation biofuels use the same material as the second one but after additional treatment, processing and modifications. The fourth generation biofuels are rather a perspective target employing such advanced technologies as in photo bioreactors and the use of intermediary organisms, e.g. algae, during production processes. In Poland, the second generation biofuels will soon have the dominant role over the first one which is positive and desired tendency.

Heat recovery systems from production processes of many types, e.g. from ventilation, from cooling, quite frequent in food industry and rarely from air conditioning as it is not very popular in Poland, or heat recovery from litter in animal farmhouses.

Photovoltaic systems, usually recognized as expensive, become reasonable when traditional connection to grid is more expensive than standards, especially when increased power demand in a farm or a household requires additional investment from regional distribution company which in turn is transferred to a user. They are treated as additional support to supply devices of low demand in complex hybrid systems (e.g. PV panels for circulation pumps in solar domestic hot water - SDHW - systems). Environmental protection aspects can be sometimes decisive if the localization is situated in nature parks. The most famous localization of this type in our country is the mountain shelter in the Valley of Five Polish Tarns. Moreover, it is also practical to install PV panels in periodically occupied small objects such as forest shelters, guest rooms and shepherd's huts but there is a need to provide an energy store system and protection in the period of no use by e.g. spare duty lighting. The potential of photovoltaics is recognized as capable to reach $12 \%$ share in total production of energy in Europe by 2020 year. Unfortunately, in Poland, there are no favorable circumstances to promote PV systems [1].

Solar walls in our climate should be completed with TIM (Transparent Insulation Material) modules besides typical massive elements and air gaps because this additional insulation protects the building envelope during fall-winter seasons against thermal losses at low ambient temperatures. It is necessary that the whole insulation of these buildings is of best quality ranging $\mathrm{u}$ value between 0.1 and 0.3 at maximum and that the terrain around is properly adapted. Several case studies can be mentioned on the basis of the author's research $[5,7]$ and the other reference [1]. Particular conclusions can be derived in relation to the application of such passive structures as Trombe-Mitchell's walls in eastern mid-European regions [7]. This typical construction cannot be successfully used for the whole year because:

- insulation even by two glass panels is insufficient for winter and

- solar radiation in summer often exceeds the needs. 
In the intermediary season of fall (spring/autumn), solar walls prove their usefulness and thus make possible to reduce heating period and energy demand in total thanks to the solar gain in several weeks within the range of the whole heating period. There is also a very useful solution to the problem of insulation, i.e. transparent panels. Thanks to the capillary structure they let radiation in and prevent from thermal losses because of air trapped within capillary and its material - organic glass - of insulation properties. Moreover, the shading can be realized by means of insulated folded blinds and with the help of leaf trees.

Because of low intensity of heat flux coming from renewable sources such as ground or solar radiation, the renewable systems have comparatively long pipelines and this is one of the reasons of thermal loss from active elements. That is also why designs should strictly reduce collective pipeline length placing collectors as close as possible to the receivers. Moreover, in comparison to traditional heating, the effectiveness of renewable systems depends more on the cycle of load. In particular, the systems that work at loads lower than calculated in the design, have much lower energy effectiveness which influences directly the costeffectiveness. The research carried out by Chochowski A. and Czekalski D. [1] prove that energy parameters outstand the predicted ones on the basis of static characteristics. Unequal load of the system in subsequent days leads to the reduction of conversion efficiency even of $50 \%$.

\section{Results}

At first, the exemplary case study of an elderly house for women in a village can be shortly described. The design of this system avoids long pipelines because the boiler room is on the ground floor directly under the roof where collectors are to be installed with proper exposition on south oriented tilted roof. The design process of this hybrid system was carried out when the total modernization of the whole object was considered, including the change of fuel from liquid gas stored in tanks on the backyard to natural gas from local network. The designed solar system was to contribute to the main supply. The designed system consists of the battery of twelve flat plate thermal collectors and nine collectors have been planned on the south tilted roof and the other three on the west roof surface with additional construction for southwest exposition. Optional expansion of the battery into another eight collectors could be possible after removal of gas tanks. The condition of source availability is fulfilled this way. Another criterion for consideration was matching the load waveform to the cycle of heat production. In this aspect there is an ideal phase coincidence either in annual cycle or daily use of hot water and heat production from the solar system. This is possible because of special care that must be carried for the residents, i.e. - because the residents are of advanced age and through this debilitated and less resistant to temperature changes, their bathing in winter must be limited to the necessitate minimum. In summer, when there is a lot of sun radiation there are no such threats as low temperature, cold draughts etc., the balneological care can be more frequently applied. There is also some good coincidence in daily treatment because the baths are taken in the afternoon hours when the house service staff have managed with cleaning and cooking and the water storage tank is full of water heated from collectors at the maximum for the day. In the evening hours, the water storage starts slowly cooling off and the staff except for the person on duty, goes home. Moreover, the residents in elderly houses do not go for holidays as housing estate inhabitants or do not go home in the afternoon as people working in offices. It is only a pity that at so many favourable circumstances, this design has been abandoned.

Czekalski D. [1] points out also some other solutions of good coincidence: a seminary with boarding house, a monastery or a convent with retreat centers, a school with a swimming 
pool, etc. Academic centers are especially vulnerable to the pressure of educative aspects of renewable energy applications and they should extremely thoroughly consider the matter of coincidence. The good solution could be a guest room house combined with a sports center containing a swimming pool available for usage during holidays. It seems not justified to supply lecture buildings from solar energy because the largest amount of energy is to be used potentially when the real use drops to zero. Then it is necessary to employ this energy somehow to avoid the destruction of the whole system. Overheated collectors are damaged and hot water stored for too long than a few days is the environment for bacteria growth. This problem has to be solved also for single family houses. In this aspect municipal applications in blocks of flats are advantageous because the part of inhabitants stays at home for the whole year and it is not a problem if this is not the same group when hot water is prepared centrally. The remaining usage is usually sufficient to ensure continuous medium flow through collectors.

Another attempt to the problem of coincidence is the consideration of the integration of an individual system with municipal grids and networks, however at the present state of formal regulations and technical practice, it is an extremely difficult enterprise in our country, available rather to bigger energy producers than just families or single farms. So far, the connection of geothermal source with the heat distribution network and the integration of boilers fuelled by biofuels with gas boilers supplied from gas distribution network or with the heat distribution network has had the best practical experience. In the case of the integration with gas boilers, the network does not receive the energy from the renewable system, only gives the possibility to reduce the amount of supplied fuel. The connection together with the receipt of energy is especially desired in the case of photovoltaic systems and the grid. The two aspect can be covered there: one of autonomous operation of a renewable system and the regular profile of power supply.

The next example of good coincidence could be the idea of integration between the production processes and solar thermal collectors studied for the case of meat production plant. Because of the meat processing, hot water of $80{ }^{\circ} \mathrm{C}$ is used to wash production rooms (intensive use at about 3 p.m.) and water of $60{ }^{\circ} \mathrm{C}$ for hygienic purposes and another processing continuously during two shifts. Hot water is supplied from cooling system recovery and steam boilers that provide also central heating in the object. The hybrid system concept suggests the integration between cooling system heat recovery and solar collectors where load cycle fits the solar daily availability waveform and conventional support from steam gas boilers.

\section{Discussion}

Some evaluation if the selected modules of a composed hybrid system is possible in advance by means of simulations. The most advanced simulation techniques are useful for designers, who in the case of not standard objects can verify their effectiveness. It is worth mentioning that RES systems are mostly unique because of the local applications, sometimes differing even between neighbor farms or buildings.

The most representative is the following software that is available in European location but with some limitations:

ESOP [4] developed by Viessman - very well prepared software, intended for use by designers but suitable also for local authority representatives. It provides calculation for some typical SDHW systems with the possibility to calculate carbon dioxide emissions and comparisons among different fuels, available in Polish version. 
TRNSYS [2] developed by University of Winconsin - advanced software to calculate transient states in the variety of systems, with the reference to geographic and climatic conditions, very useful also for advanced use such as scientific analysis and for designers, however comparatively expensive and Polish version is not available. It is worth mentioning that the university provides some possibilities for free download from internet and even these limited versions are very educative and thus very useful for didactics. The software is grouped in packages for different media and RES and enables cost calculation on the basis of design system and selected devices from USA market.

WUFI [3] developed by Fraunhoffer Institute - software suitable for passive systems such as multi-layer wall structures, available in Polish version also for free download for the purpose of didactics but with limitations, provides some information to know particular producers of the used materials and thus can be useful to calculate the cost of the system.

Moreover, the authors can also mention simulation algorithms based on equivalent thermal network developed in cooperation by Lublin Technical University and the University of Life Science in Warsaw [5, 6]. These algorithms at the current state are suitable for advanced users, perform calculations also for transient states and have not been commercialized yet. The use of these algorithms is undoubtedly more time consuming but the user can decide on all simplifications introduced to the system model and to the calculations. The method enables modeling of energy flow by means of different media and thus is suitable for integrated systems, provides results of calculated energy flux, flows and temperature reached in the system units in time for different days of a year in the form of graphs and matrices. The other algorithms have been developed for solar walls by means of FEM analysis.

What is even more important the ease of simulation analysis can add the value to the planned refurbishments and all purpose modernizations in many municipal sectors in the phase prior to the design instead of time consuming and expensive existing building inventorying in situ. This should be particularly taken into account when numerous objects are to be rebuild in the regions where older technology have been applied so far.

\section{References}

[1] D. Chwieduk, R. Domański, et al., Renewable Energy. Innovative Technology and New Ideas., Chwieduk D., Domański R., Jaworski M. (editors) Warsaw 2008, p. 476.

[2] http://sel.me.wisc.edu/trnsys Oct.'10.

[3] http://www.wufi.de Oct.'10.

[4] Viessmann, ESOP v.2.0 CD, 23.03.2003

[5] Wójcicka-Migasiuk D., Modelling hybrid systems in rural regions, (in Polish) Inżynieria Rolnicza 1(89)/24, KTR PAN PTIR, Kraków 2007, p. 120.

[6] Wójcicka-Migasiuk D., Nodal potential simulation for the analysis and design of SDHW systems. (in Polish) Acta Agrophysica No. 39/2001, Inst. Agrofizyki PAN, Lublin 2001, p. 106.

[7] Wójcicka-Migasiuk D., Heat transfer through solar walls, (in Polish) LTN, Lublin 2008, p. 112. 